\title{
An association of membrane-damaging toxins from coagulase-negative staphylococci and chronic orofacial muscle pain
}

\author{
H. L. BUTT, R. H. DUNSTAN*, N. R. McGREgOR†, T. K. ROBERTS*, MARIANN ZERBES* \\ and I. J. KLINEBERG†
}

Collaborative Pain Research Unit (CPRU), Division of Microbiology and Infectious Disease, Hunter Area Pathology Service, John Hunter Hospital, Newcastle, *Department of Biological Sciences, University of Newcastle, Newcastle and †Faculty of Dentistry, University of Sydney, Westmead Hospital, Westmead, Australia

\begin{abstract}
Forty-six patients presenting with chronic orofacial muscle pain and eight age- and sexmatched control subjects were investigated for the carriage prevalence of, and exotoxin production by, coagulase-negative staphylococci (CNS). The eight control subjects were selected from an initial group of 41 subjects on the basis of the absence of musculoskeletal symptoms. There was a significantly higher prevalence and multiple carriage of four or more strains of CNS in patients with chronic muscle pain than in control subjects ( 23 versus 9 isolates/10 subjects). Two of the 103 CNS isolates from patients with muscle pain and none from the control subjects produced toxic shock syndrome toxin 1 (TSST-1), suggesting that pyrogenic toxins do not significantly contribute to the aetiology of chronic muscle pain. There was a significantly higher prevalence of $\delta$-haemolysin (41 of 114) and 'horse'-haemolysin (56 of 114) production by CNS isolates from patients with chronic muscle pain compared with those from control subjects. None of the control subjects was colonised with CNS that produced significant amount of either $\delta$ - or 'horse'-haemolysin, whereas 35 of 44 patients with chronic orofacial muscle pain were colonised with CNS that produced significant amounts of 'horse'-haemolysin, 37 that produced $\delta$-haemolysin and 33 that produced both $\delta$ - and horse-haemolysin. This study suggests that membrane-damaging toxins, like $\delta$ - and 'horse'-haemolysin, may play a role in the aetiology of chronic orofacial muscle pain.
\end{abstract}

\section{Introduction}

Chronic orofacial muscle pain (craniomandibular) disorders form part of the group of chronic musculoskeletal pain conditions, symptoms of which can be detected in up to $75 \%$ of the population, with severe forms occurring in $5-10 \%$ of subjects $[1,2]$. The aetiology of these conditions is unknown, but hypotheses include both physical and psychological aetiologies [1, 2]. Patients with chronic muscle pain report symptoms predominantly in an axial skeletal distribution with increased sternal and limb pain in more severe forms [3]. These clinical signs and symptoms have been strongly associated with recurrent infective disease processes in a previous study [4]. These patients reported an increased prevalence of recurrent upper respiratory and genitourinary infective events at

Received 1 April 1997; revised version accepted 6 Nov. 1997.

Corresponding author: Dr R. H. Dunstan. or preceding onset, but with no reported evidence for increased prevalence of viral infections such as measles, mumps and glandular fever [5]. Examination of genitourinary microbial flora revealed a higher carriage rate of coagulase-negative staphylococci (CNS) in patients with chronic muscle pain than in sex-matched controls, suggesting an association between CNS carriage and chronic muscle pain [6].

The role of CNS in disease processes has not been well defined. Gemmell and Schumacher-Perdreau [7] demonstrated that $\mathrm{CNS}$ can produce as many as eight exotoxins that could contribute to virulence. Of these exotoxins, a membrane-damaging toxin resembling Staphylococcus aureus $\delta$-toxin showed the greatest biological activity. Cytotoxicity studies with human embryonic lung fibroblasts demonstrated that this CNS membrane-damaging toxin caused preferential release of cell constituents and cellular swelling [8]. Another membrane-damaging exotoxin, $\alpha$-toxin, had been shown to permeabilise smooth muscle cells $[9,10]$, 
suggesting that staphylococcal membrane-damaging exotoxins may interfere with the excitation-coupling mechanisms of smooth muscle.

The purpose of this study was to investigate the carriage prevalence of staphylococci in patients with chronic orofacial muscle pain and a group of symptom-free control subjects and to assess the ability of these organisms to produce membrane-damaging and other exotoxins.

\section{Materials and methods}

\section{Patient and control subject selection}

Forty-six patients presenting for management of chronic orofacial muscle pain were recruited; however, two patients were excluded because of laboratory sample errors. Patients were selected to comply with the group 1 (muscle disorders), category 1a (myofascial pain) of the orofacial research diagnostic criteria [2]. Inclusion criteria were as follows: (1) symptoms of orofacial muscle pain; (2) a positive response to a visual analogue pain scale (VAS) of average pain intensity in the 2 weeks before consultation; (3) the presence of palpable muscle pain in the reported pain areas; (4) that the pain was present on $>50 \%$ of days during the 3 months immediately preceding consultation; and (5) palpation of head, neck and shoulder muscles $[11,12]$ in the sites reported to be painful was positive. Exclusion criteria were as follows: (1) pain associated with the teeth, temporomandibular joint (TMJ) clicking or arthritis and crepitation, sinusitis, salivary glands, nerve or vessel pathology; (2) reporting of pain without associated palpable muscle tenderness.

To select a control group without any musculoskeletal symptoms, the initial 41 control subjects were further screened on the basis of: (1) a nil response to questions from the Hopkins Symptom Check List-90Revised (SCL-90-R) questions Q12 - chest pain, Q27 - low back pain, Q42 - muscle soreness, Q56 - body weakness and Q58 - heavy feelings in limbs [13]; (2) no evidence of palpable muscle pain; (3) no response to the VAS of average pain intensity in the previous 12 weeks: and (4) had not sought professional advice or treatment for chronic muscle pain in the previous 12 months. Acute pain associated with trauma during the preceding 12 months was not a criterion for exclusion. From an initial group of 41 control subjects, eight age- and sex-matched subjects who complied with the highly restrictive symptom definition were recruited. Each patient and control subject provided informed consent and was interviewed and assessed by one clinician (N.R.M.).

\section{Specimen collection and processing}

Nose swabs, and vaginal swabs from female participants, were collected and transported in Stuart's medium (Transystem, Interpath Services $P / L$ ), and cultured on Columbia horse blood agar (Oxoid). The presence of occlusal splint was not considered an important factor in determining the changes in microbial flora in sampling sites, as only four patients with pain were wearing the splints at the time of sampling. After incubation for $24 \mathrm{~h}$ at $35^{\circ} \mathrm{C}$, all cultures were examined with a stereomicroscope (Zeiss, Germany) for different morphological types of staphylococcal isolates. A single colony representing a morphological type was streaked on to horse blood agar and incubated at $35^{\circ} \mathrm{C}$ for a further $24 \mathrm{~h}$. Experience from a previous study [5] demonstrated the necessity of sampling a minimum of three colonies of a morphological type from each site to establish adequate representation. Cultures with a positive Gram's stain and catalase reaction were then identified according to their biochemical characteristics.

\section{Identification}

Staphylococcal isolates were identified by the methods of Kloos and Bannerman [14], Herbert et al. [15] and Kloos and Schleiffer [16]. Carbohydrates in Purple Agar Base (Difco) and other test reagents were prepared, sterilised and added to eight wells in the 12 strips of a microtitration plate. Each strip of eight wells was prepared as follows: $5 \mu \mathrm{l}$ of a sterile carbohydrate $20 \%$ solution was placed in the first six wells, $100 \mu 1$ each of urease and nitrate solution was transferred to the remaining two wells, and $95 \mu$ l of sterile purple agar was added to the first six wells with the carbohydrate solution and mixed gently. Each well of each row contained a different carbohydrate/reagent solution. A solution of staphylococcal culture in saline prepared to a turbidity of a 0.5 MacFarland standard was used as the inoculum. The six carbohydrates tested in each strip were lactose, maltose, trehalose, mannitol, sucrose and mannose. Only strains that were susceptible to furazolidone $(100 \mu \mathrm{g})$ and resistant to bacitracin $(0.04 \mathrm{U})$ were included in this study [15]. A tube coagulase test with citrated rabbit plasma was used to differentiate the $S$. aureus group from the CNS group. A positive coagulase reaction with human plasma and a positive ornithine decarboxylase activity were used for the confirmation of $S$. lugdunensis [17]. Resistance to the antibiotics novobiocin $(5 \mu \mathrm{g})$ and polymyxin $\mathrm{B}$ $(300 \mathrm{U})$ were included in the differentiation of $S$. saprophyticus and $S$. epidermidis, respectively, from other related species [15]. Similarly, bacitracin (10 U) was included to help differentiate $S$. haemolyticus from other novobiocin-susceptible staphylococci [15]. All equivocal identifications were confirmed with an API Staph kit (bioMérieux, France).

\section{Staphylococcal supernate}

Staphylococcal strains were cultured in $5 \mathrm{ml}$ of Brain Heart Infusion Broth (Oxoid) at $35^{\circ} \mathrm{C}$ for a minimum of $18 \mathrm{~h}$. Cultures were centrifuged at $25000 \mathrm{~g}$ at $4^{\circ} \mathrm{C}$ 
for $20 \mathrm{~min}$ and each supernate was filtered through a $0.22-\mu \mathrm{m}$ membrane filter (Millipore, Bedford, USA). Each strain was tested for toxic shock syndrome toxin1 (TSST-1), enterotoxins A-D (SEA-SED) and haemolysin production.

\section{Detection of TSST-1 and SEA-SED}

Staphylococcal TSST-1 and enterotoxin types A, B, C and $\mathrm{D}$ were detected by the reverse passive latex agglutination kits (SET, and TSST-RPLA, Oxoid), used as microslide agglutination tests as described by Murrell et al. [18]. Positive and negative known controls accompanied each test sample. Agglutination was observed with phase contrast microscopy.

\section{Assay for haemolytic activity}

Rabbit, sheep, horse and human type ' $O$ ' red blood cells were washed three times in $1 \mathrm{mM} \mathrm{MgPBS}(0.5 \mathrm{M}$ $\mathrm{KH}_{2} \mathrm{PO}_{4}, 0.5 \mathrm{M} \mathrm{KH} \mathrm{KO}_{4}, 1 \mathrm{mM} \mathrm{MgSO}_{4}$ ) and a final $1 \% \mathrm{v} / \mathrm{v}$ of each of the four red cell types was prepared. An equal volume of the sterilised staphylococcal supernate was added to each of the four $1 \% \mathrm{v} / \mathrm{v}$ red cell pellets. The suspensions were mixed and incubated at $35^{\circ} \mathrm{C}$ for $30 \mathrm{~min}$. The 'hot-cold' effect of $\beta$ haemolysin on sheep red cells was demonstrated by a further incubation at $4^{\circ} \mathrm{C}$ for $1 \mathrm{~h}$. The 'heat stable' effect of $\delta$-haemolysin was demonstrated by heating the staphylococcal supernate at $80^{\circ} \mathrm{C}$ for $15 \mathrm{~min}$ before incubation with human red cells [19]. The 'heat stable' effect of 'horse'-haemolysin was also investigated. After incubation, all suspensions were centrifuged for $5 \mathrm{~min}$ and the absorbence of each supernate was determined at $541 \mathrm{~nm}$. A sample substituting de-ionised water for MgPBS with each of the four red cell types was measured at neat to represent $100 \%$ haemolysis and at 1 in 2 and 1 in 4 dilutions. Haemolytic activities of samples were calculated from a standard curve.

\section{Definition of positive (significant) haemolysis}

Positive haemolysis for each of the four haemolysins was defined as a value $\geqslant 2 \mathrm{SD}$ above the mean haemolysis produced by staphylococcal strains from control subjects, thus representing a high value seen in only $2.5 \%$ of a normally distributed population. The mean haemolysis percentage and SD for the four haemolysins produced by staphylococcal isolates from control subjects were: for $\alpha$-haemolysin, $2.6 \%$ and $7.8 \%$ respectively; $\beta$-haemolysin, $10.1 \%$ and $19.7 \% ; \delta$ haemolysin, $0.7 \%$ and $1.2 \%$; and 'horse'-haemolysin, $2.5 \%$ and $2.2 \%$. Positive (significant) haemolysis for each of the four haemolysins was therefore defined as: $>18.1 \%$ for $\alpha$-haemolysin; $>49.5 \%$ for $\beta$-haemolysin; $>3.1 \%$ for $\delta$-haemolysin and $>6.9 \%$ for 'horse'haemolysin. Negative haemolysis for each of the four haemolysins included all values that were less than two SD above the mean haemolysis of control staphylococcal strains.

\section{Statistical analysis}

Prevalence differences between the two clinical groups were compared by the $\chi^{2}$ test with Yates' correction when appropriate. Fisher's exact probability test was used when detection frequency was less than one. Staphylococcal isolates with similar biochemical characteristics isolated from different sites in the same individual were counted as one organism type. Isolates with similar biochemical characteristics from the same individual but producing different membrane-damaging or pyrogenic toxins were defined as different organisms.

\section{Results}

\section{Patient and control subjects characteristics}

The mean age of the 44 patients with muscle pain and the eight control subjects was similar with $37.6 \mathrm{SD}$ 16.5 years (range 16-57 years) for the control subjects and $38.3 \mathrm{SD} 10.5$ years (range 20-56 years) for the muscle pain patients. The sex ratio (male:female) for the muscle pain group was 1:3, compared with $1: 2.7$ for the control subjects.

\section{Relationship between coagulase-positive and -negative staphylococci}

A total of 125 staphylococcal isolates was obtained from the study; 11 isolates were from control subjects and 114 from patients with chronic muscle pain (Table 1). Fifteen of 125 isolates were $S$. aureus and 110 were CNS. Of the $15 \mathrm{~S}$. aureus isolates, four were from control subjects and 11 from patients with chronic muscle pain. This prevalence of $S$. aureus per 10 subjects was higher in controls than in patients with chronic muscle pain (five versus three isolates, respectively). By contrast there was a higher prevalence of CNS in patients with chronic muscle pain (23 isolates/10 patients) than in control subjects (9 isolates $/ 10$ subjects, $\mathrm{p}<0.01$ ), suggesting that patients with chronic orofacial muscle pain were predisposed to multiple colonisation with CNS. The distribution of staphylococcal isolates at the two anatomical sites (nose and genital tract) between chronic muscle pain patients and control subjects was not significantly different. The $110 \mathrm{CNS}$ strains were further examined according to their biochemical characteristics (Table 1). Six CNS species were identified in the study; $S$. epidermidis, $S$. haemolyticus and $S$. xylosis were represented in each of the two clinical groups whereas S. warneri, S. hominis and S. lugdunensis were isolated only from the patients with muscle pain. This difference in species distribution was not significant, suggesting that there was no dominance of any particular staphylococcal species.

\section{Multiple staphylococcal carriage}

Control subjects and patients with muscle pain were screened for the incidence of multiple staphylococcal 
Table 1. Colonisation incidence of coagulase-positive and coagulase-negative staphylococcal spp. from control subjects $(n=8)$ and patients with chronic muscle pain $(\mathrm{n}=44)$

\begin{tabular}{lcc}
\hline Organisms & $\begin{array}{c}\text { Control subjects } \\
\text { (nose, genital) }\end{array}$ & $\begin{array}{c}\text { Chronic pain patients } \\
\text { (nose, genital) }\end{array}$ \\
\hline $\begin{array}{l}\text { Total staphylococcal spp. } \\
\text { total incidence }\end{array}$ & $11(7,4)$ & $114(59,55)$ \\
$\quad$ incidence/10 subjects & 14 & 25 \\
Coagulase-positive staphylococcus (S. aureus) & $4(4,0)$ & $11(9,2)$ \\
total incidence* & 5 & 3 \\
incidence/10 subjects & & $103(50,53)$ \\
CNS & $7(3,4)$ & 23 \\
total incidence* & 9 & 32 \\
incidence/10 subjects & 3 & 12 \\
$S$. epidermidis & 0 & 11 \\
$S$. warneri & 2 & 16 \\
$S$. haemolyticus & 0 & 14 \\
$S$. hominis & 0 & 18 \\
$S$. lugdunensis & 2 & \\
$S$. xylosis & &
\end{tabular}

carriage. Of the 44 patients with chronic muscle pain, $38(86.4 \%, \mathrm{p}<0.008)$ were each colonised by two or more CNS strains, and $23(52.3 \%, \mathrm{p}<0.006)$ were each colonised by three or more staphylococcal strains (Table 2). Twelve of these 23 patients with muscle pain with multiple carriage were also found to be colonised with four or more different strains of CNS. By comparison three $(37.5 \%)$ control subjects were colonised by two CNS strains and the remaining five $(62.5 \%)$ subjects by one or no strains.

\section{Staphylococcal pyrogenic toxins}

The possibility that staphylococcal isolates from patients with chronic muscle pain may produce pyrogenic toxins was investigated. All staphylococcal isolates from the two clinical groups were screened for the production of enterotoxins A, B, C and D and TSST- 1 . The four $S$. aureus isolates from control subjects produced five pyrogenic toxins (Table 3). Conversely, only four of the $11 \mathrm{~S}$. aureus isolates from patients with muscle pain produced pyrogenic toxins. Five of the $103 \mathrm{CNS}$ isolates from patients with muscle pain and none from the seven control CNS strains produced pyrogenic toxins. From these data no significant association was found between the production of
Table 2. Incidences of control subjects $(n=8)$ and chronic muscle pain patients $(\mathrm{n}=44)$ colonised with multiple staphylococcal carriage

\begin{tabular}{lcc}
\hline $\begin{array}{l}\text { Number of } \\
\text { CNS spp. }\end{array}$ & $\begin{array}{c}\text { Control subjects } \\
(\%)\end{array}$ & $\begin{array}{c}\text { Chronic muscle } \\
\text { pain patients (\%) }\end{array}$ \\
\hline 0 & 1 & 0 \\
1 & 4 & $6(13.6)$ \\
2 & 3 & $15(34.1)$ \\
3 & 0 & $11(25.0)$ \\
$\geqslant 4$ & 0 & $12(27.3)$ \\
\hline
\end{tabular}

Significance test: $\chi^{2}, \geqslant 2$ CNS spp., $\mathrm{p}<0.008$; Fisher's exact probability, $\geqslant 3$ CNS spp., $\mathrm{p}<0.006$.

TSST-1 and enterotoxins amongst the muscle pain and control isolates, suggesting that pyrogenic toxins do not significantly contribute to the aetiology of chronic muscle pain.

\section{Staphylococcal membrane-damaging toxins}

All staphylococcal isolates from the study were examined for haemolysin activity as defined in Materials and methods (Table 4). There was a significantly higher prevalence of haemolysis of red cells by isolates from patients with chronic muscle pain ( 60 of $114,53 \%$ ) compared with those from the control subjects $(2$ of $11,18 \%)(\mathrm{p}<0.03)$. The incidence of $S$.

Table 3. Enterotoxins and TSST-1 production by control and muscle pain staphylococcal isolates

\begin{tabular}{|c|c|c|c|c|}
\hline \multirow[b]{2}{*}{ Toxin } & \multicolumn{2}{|c|}{ Control isolates } & \multicolumn{2}{|c|}{ Muscle pain isolates } \\
\hline & $S$. aureus $(\mathrm{n}=4)$ & CNS $(n=7)$ & S. aureus $(\mathrm{n}=11)^{*}$ & CNS $(n=103)^{*}$ \\
\hline \multicolumn{5}{|c|}{ Enterotoxin } \\
\hline A & 1 & - & - & 2 \\
\hline $\mathrm{B}$ & - & - & - & 1 \\
\hline $\mathrm{C}$ & 1 & - & 2 & - \\
\hline $\mathrm{D}$ & - & - & 1 & - \\
\hline TSST-1 & 3 & - & 1 & 2 \\
\hline Total & 5 & 0 & 4 & 5 \\
\hline
\end{tabular}

*Not significant: $\chi^{2}$ test with 'Yates' corrections. 
Table 4. Incidence of positive and negative haemolysin from control $(\mathrm{n}=11)$ and muscle pain CNS isolates $(\mathrm{n}=114)$

\begin{tabular}{|c|c|c|}
\hline Isolates & Negative & Positive \\
\hline \multicolumn{3}{|c|}{ Total staphylococcal isolates* } \\
\hline Control $(n=11)$ & 9 & 2 \\
\hline Muscle pain $(n=114)$ & 54 & 60 \\
\hline \multicolumn{3}{|l|}{ S. aureus only ${ }^{\dagger}$} \\
\hline Control $(n=4)$ & 3 & 1 \\
\hline Muscle pain $(\mathrm{n}=11)$ & 6 & 5 \\
\hline \multicolumn{3}{|l|}{ CNS only ${ }^{\ddagger}$} \\
\hline Control $(\mathrm{n}=7)$ & 6 & 1 \\
\hline Muscle pain $(\mathrm{n}=103)$ & 39 & 64 \\
\hline
\end{tabular}

aureus isolates from patients with chronic muscle pain that produced haemolysin (5 of $11,46 \%$ ) was higher than, but not significantly different to, that from control subjects ( 1 of $4,25 \%)$. By contrast, $64(62 \%)$ of the 114 CNS strains from patients with chronic muscle pain but only one of seven $(14 \%)$ CNS strains from control subjects were haemolysin positive $(p<0.04)$, suggesting that CNS from patients with chronic muscle pain were associated with increased production of membrane-damaging toxins.

\section{Staphylococcal $\alpha, \beta, \delta$ and 'horse'-haemolysins}

In this study, four staphylococcal membrane-damaging toxins ( $\alpha, \beta, \delta$ and 'horse'-haemolysins) were examined to determine if they were responsible for the observed increased prevalence of haemolysin produc- tion among staphylococcal isolates from the muscle pain group. One of the 11 control isolates and 10 $(8.7 \%)$ of 114 muscle pain-associated isolates produced $\alpha$-haemolysins causing significant haemolysis to rabbit red cells (Table 5). Similarly, only one of 11 control isolates and one $(<1 \%)$ of 114 muscle pain-associated isolates produced $\beta$-haemolysins resulting in significant haemolysis to sheep red cells. These data indicate that $\alpha$ - and $\beta$-haemolysins were not associated with the observed increased prevalence of haemolysin production among staphylococcal isolates. When strains were examined for $\delta$-haemolysins, $41(36 \%)$ of the muscle pain-associated isolates produced significant haemolysis of human red cells compared with none of the control isolates $(p<0.04)$. There was also a highly significant difference in the haemolytic activity with horse red cells between the two clinical groups; 56 (49.1\%) of 114 muscle pain-associated CNS isolates produced significant haemolysis of horse red cells compared with none of the control strains $(p<0.005)$. Of the 114 muscle pain-associated strains examined, the incidence of positive $\delta$-haemolysis was found to be similar in strains of $S$. warneri $(66.7 \%), S$. haemolyticus $(54.5 \%)$, S. lugdunensis $(50.0 \%)$ and $S$. hominis $(43.8 \%)$, which was significantly higher than those observed in $S$. aureus $(18.2 \%, \mathrm{p}<0.05)$ and $S$. epidermidis $(15.6 \%, \mathrm{p}<0.05)$ (Table 6). Similarly, the incidence of positive 'horse'-haemolysis was similar with all the CNS, but lower with $S$. aureus. None of the eight control subjects was colonised with staphylococci that produced positive $\delta$ or 'horse'haemolysins, or both. By contrast, $39(88.6 \%)$ of the 44 chronic orofacial muscle pain patients were colonised with at least one CNS producing either positive $\delta$ - or

Table 5. Incidence of staphylococcal $\alpha, \beta$ and $\delta$-haemolysins from control and muscle pain isolates

\begin{tabular}{lccccc}
\hline & \multicolumn{2}{c}{ Control isolates $(\mathrm{n}=11)$} & & \multicolumn{2}{c}{ Muscle pain isolates $(\mathrm{n}=114)$} \\
\cline { 5 - 6 } Haemolysin & Negative & Positive & & Negative & Positive \\
\hline$\alpha^{*}$ & 10 & 1 & & 104 & 10 \\
$\beta$ & 10 & 1 & & 113 & 1 \\
$\delta^{\dagger}$ & 11 & 0 & & 73 & 41 \\
'horse' & 11 & 0 & & 58 & 56 \\
\hline
\end{tabular}

Positive haemolysis was defined as the percentage haemolysis $\geqslant 18.1 \%$ for $\alpha$-haemolysis, $49.5 \%$ for $\beta$-haemolysis, $3.1 \%$ for $\delta$-haemolysis and $6.9 \%$ for 'horse'-haemolysin.

*Not significant, $\chi^{2}$ test with Yates' correction.

${ }^{\dagger} \mathrm{p}<0.04$, Fisher's exact probability test.

${ }_{\mathrm{p}} \mathrm{p}<0.05$, Fisher's exact probability test.

Table 6. Incidence of staphylococcal species $(n=114)$ from muscle pain patients producing $\delta$ - and 'horse'-haemolysins causing significant haemolysis of human and horse red cells

\begin{tabular}{lccc}
\hline Staphylococcal spp. & $\begin{array}{c}\text { Number of } \\
\text { isolates }\end{array}$ & $\begin{array}{c}\text { Positive } \delta \text {-haemolysis } \\
(\%)\end{array}$ & $\begin{array}{c}\text { Positive 'horse'-haemolysis } \\
(\%)\end{array}$ \\
\hline S. aureus & 11 & $2(18.2)$ & $3(27.3)$ \\
S. epidermidis & 32 & $5(15.6)$ & $18(56.3)$ \\
S. warneri & 12 & $8(66.7)$ & $9(75.0)$ \\
S. haemolyticus & 11 & $6(54.5)$ & $5(45.5)$ \\
S. hominis & 16 & $7(43.8)$ & $5(31.3)$ \\
S. lugdunensis & 14 & $7(50.0)$ & $6(42.9)$ \\
S. xylosis & 18 & $6(33.3)$ & $10(55.6)$ \\
\hline
\end{tabular}


'horse'-haemolysis: 35 (79.5\%) were colonised with CNS strains producing positive 'horse'-haemolysin $(\mathrm{p}<0.00001), 37(84.1 \%)$ with positive $\delta$-haemolysis $(\mathrm{p}<0.00001)$, and $33(75 \%)$ with both $\delta$ - and 'horse'haemolysis $(\mathrm{p}<0.0001)$.

\section{Discussion}

Comparison of patients with chronic orofacial muscle pain and symptom-free control subjects showed marked differences in the carriage of CNS and their production of membrane-damaging toxins. The high prevalence of multiple carriage of CNS species seen in this study in patients with chronic orofacial muscle pain was consistent with previous observations [6]. In an investigation of staphylococcal nasal carriage in medical students, Kingdom et al. [20] obtained 291 CNS isolates from 197 students, yielding a ratio of 12.7 strains for every 10 students studied. This colonisation prevalence of CNS was similar to the isolation frequency of nine strains per 10 control subjects seen in the present study. In a separate study [21], an attempt was made to determine the carriage of antibiotic-resistant CNS in patients with acne vulgaris. A total of 97 strains of CNS was isolated from the skin of 64 patients, giving a ratio of 15 strains for every 10 patients. In the present study, where strict criteria were applied to incidence occurrence, 23 strains of CNS were isolated from every 10 patients with chronic orofacial muscle pain, a colonisation prevalence nearly two-fold higher than observed in the medical student study [20] and 1.6-fold higher than observed in the acne vulgaris study [21]. The wearing of occlusal splints, which is a common treatment modality in orofacial pain patients $[1,2]$ was unlikely to be an important factor in alteration of the microbial flora as only four $(9.1 \%)$ of the 44 were wearing such devices at the time of sampling. These data suggest that multiple carriage of CNS strains may be a significant and characteristic feature in patients with chronic orofacial muscle pain.

This study has shown that CNS are capable of producing TSST-1 or enterotoxins, or both. The incidence of CNS from healthy individuals producing TSST-1 has previously been reported to be between $0.6 \%$ and $1.7 \%(22)$. The data from the present study showing that $1.9 \%$ of CNS produced TSST-1 was in agreement with this finding. Despite the finding that CNS from patients with chronic orofacial muscle pain can produce TSST-1, the low prevalence of these pyrogenic organisms is unlikely to cause significant pathology in this syndrome.

The ability of CNS to cause disease is now well accepted. CNS were the most frequent organisms isolated from neonates with necrotising enterocolitis (NEC) and was associated with both morbidity and mortality [23]. The morbidity of NEC was shown to be significantly associated with patients colonised with CNS capable of producing cytotoxic amounts of $\delta$ haemolysin [24, 25]. Gemmell [8] monitored the toxigenic ability of commensal CNS from healthy individuals and found that $13 \%$ of the strains produced $\delta$-haemolysin. In the present, $51.8 \%$ of CNS from patients with chronic orofacial muscle pain produced $\delta$-haemolysin, a prevalence similar to the finding of Gemmell and Roberts [26], where $65 \%$ of CNS from patients with urinary tract infections and $50 \%$ of CNS isolated from blood, abscess and wound infections produced $\delta$-haemolysin. Interestingly, the increased prevalence of staphylococcal urinary tract infections in young females [27] coincides with the increase in prevalence in reporting of orofacial muscle pain $[1,28]$. These data suggest that patients with chronic orofacial muscle pain, although clinically noninfective, may have subclinical pathology occurring at cellular level resulting in reversible cell damage.

The data from this study indicate that CNS isolates producing $\alpha$ - and $\beta$-haemolysins were not significantly associated with patients with chronic muscle pain, but $\delta$ - or 'horse'-haemolysin producing strains, or both, were recovered from $89 \%$ of the chronic muscle pain patients and none of the control subjects. The in-vivo importance of $\delta$-haemolysin as a virulent factor affecting host membranes has always been controversial. $\delta$-Haemolysin from CNS is a hexameric molecule of 25 amino acid residues with activities and a molecular homology to the 26 amino acid residues of $\delta$-haemolysin from $S$. aureus $[29,30]$. The activities of $\delta$-haemolysin correlate directly with their ability to permeabilise cell membranes resulting in channel formation consisting of a cluster of $\alpha$-helical molecules [31]. The in-vivo role of $\delta$-haemolysin as a virulence factor has been challenged, as serum lipoproteins and bactericidal lipids such as 2-monoglyerides and unsaturated fatty acids can neutralise $\delta$ haemolysin activity [32, 33]. However, Long and Kapral [34] demonstrated the ability of CNS to produce fatty acid modifying enzymes (FAME) that inactivate both 2 -monoglycerides and unsaturated fatty acids by esterifying the fatty acid moieties to cholesterol. Triglycerides with unsaturated fatty acid side-chains produced by the host were shown to be potent inhibitors of FAME [35]. Triglycerides in turn could be inactivated by bacterial lipase, a lipolytic exoenzyme, produced by CNS and other organisms [36]. This series of measures and countermeasures in host-parasite relationships supports the concept of host membrane permeabilisation by staphylococcal $\delta$ haemolysin.

The wide spectrum of cytolytic activity of $\delta$ haemolysin has been well reported. $\delta$-Haemolysin is known to lyse both human and horse red cells [37]. The significant differences in the incidence of haemolytic activity shown in this study between human and horse red cells may confirm the broad 
but different cytolytic activity of $\delta$-haemolysin. However, the results may also support the possibility of a different membrane-damaging toxin from CNS, 'horse'-haemolysin. Turner and Pickard [38] reported a haemolysin from $S$. aureus that lyses horse red cells and with activities distinct from $\alpha-, \beta$ - and $\delta$ haemolysin. Not unlike $\delta$-haemolysin, 'horse'-haemolysin could withstand heating to $80^{\circ} \mathrm{C}$ without loss of activity [38] - a feature used in this study to highlight the probable presence of this new toxin. Furthermore, activities of 'horse'-haemolysis from each staphylococcal species observed in this study was uniformly and consistently different with the corresponding activities of $\delta$-haemolysin providing further support for the concept of a different toxin. In view of the significant association of membrane-damaging toxins from CNS and chronic orofacial muscle pain the identity and characteristics of this new 'horse'haemolysin require urgent investigation.

The data from this study indicate that multiple carriage of CNS was associated with chronic orofacial muscle pain. The CNS isolates from $89 \%$ of the patients with chronic muscle pain produced significant $\delta$ - or 'horse'-haemolysins, or both, whereas those isolates from an ideal musculoskeletal symptom-free control group of subjects did not. It is proposed that CNS producing $\delta$ - or 'horse'-haemolysins, or both, are highly associated with the aetiology of chronic orofacial muscle pain.

\section{References}

1. McNeill C. Management of temporomandibular disorders: concepts and controversies. $J$ Prosthet Dent 1997; 77: $510-522$.

2. Okeson JP. Orofacial pain: guidelines for assessment, classification, and management. Chicago, Quintessence Publishing. 1996.

3. McGregor NR, Butt HL, Zerbes M, Klineberg IJ, Dunstan RH, Roberts TK. Assessment of pain (distribution \& onset). Symptoms, SCL-90-R Inventory responses, and the association with infectious events in patients with chronic orofacial pain. $J$ Orofac Pain 1996; 10: 339-350.

4. McGregor NR, Butt HL, Klineberg IJ. Chronic craniocervical myalgia: association with genitourinary infection, a pilot study. $J$ Dent Res 1992; 32: 45.

5. McGregor NR, Butt HL, Klineberg IJ. Myogenous craniomandibular disorders: a preliminary report of a possible systemic etiology. J Orofac Pain 1993; 7: 108.

6. Zerbes M, Butt HL, McGregor NR, Klineberg IJ. Toxin producing staphylococci from patients with chronic muscle pain/fatigue. Australian Microbiologist 1993; 14: A62.

7. Gemmell CG, Schumacher-Perdreau F. Extracellular toxins and enzymes elaborated by coagulase-negative staphylococci. In: Mardh PA, Schleifer KH (ed) Coagulase-negative staphylococci. Stockholm, Almqvist and Wiksell. 1986: 109-121.

8. Gemmell CG. Extracellular toxins and enzymes of coagulasenegative staphylococci. In: Easmon CSF, Adlam C (ed) Staphylococci and staphylococcal infections, vol 2: the organism in vivo and in vitro. London, Academic Press. 1983: 809-827.

9. Ono T, Mita M, Suga O, Hashimoto T, Oishi K, Uchida MK. Receptor-coupled shortening of $\alpha$-toxin-permeabilized single smooth muscle cells from the guinea-pig stomach. $\mathrm{Br} J$ Pharmacol 1992; 106: 539-543.

10. Nishimura J, Kolber M, van Breemen C. Norepinephrine and
GTP- $\gamma$-S increase myofilament $\mathrm{Ca}^{2+}$ sensitivity in $\alpha$-toxin permeabilized arterial smooth muscle. Biochem Biophys Res Commun 1988; 157: 677-683.

11. Helikimo MI, Bailey J, Ash MM. Correlation of the electromyographic silent period duration and the Helikimo dysfunction index. Acta Odontol Scand 1979; 37: 51-56.

12. Wolfe F, Smythe HA, Yunus MB et al. The American College of Rheumatology 1990 criteria for the classification of fibromyalgia. Report of the Multicenter Criteria Committee. Arthritis Rheum 1990; 33: 160-172.

13. Derogatis LR. 1975 SCL-90-R administration, scoring and procedures manual - II for the revised version and other instruments of the psychopathology rating scale series. Clinical Psychometrics Research. Towson, MD. 21204.

14. Kloos WE, Bannerman TL. Staphylococcus and micrococcus In: Murray PR et al (eds) Manual of Clinical Microbiology. Washington, American Society for Microbiology. 1995.

15. Hébert GA, Crowder CG, Hancock GA, Jarvis WR, Thornsberry $C$. Characteristics of coagulase-negative staphylococci that help differentiate these species and other members of the family Micrococcaceae. J Clin Microbiol 1988; 26: 1939-1949.

16. Kloos WE, Schleifer KH. Simplified scheme for routine identification of human Staphylococcus species. $J$ Clin Microbiol 1975; 1: 82-88.

17. Bes M, Fleurette J, Freney J, Brun Y. Identification of Staphylococcus lugdunensis and Staphylococcus schleiferi. In: Jeljaszewics J, Ciborowski P (eds) The Staphylococci. NY, Gustav Fischer Verlag. 1989: 111-112.

18. Murrell WG, Stewart BJ, O’Neill C, Siarakas S, Kariks S Enterotoxigenic bacteria in the sudden infant death syndrome. $J$ Med Microbiol 1993; 39: 114-127.

19. Möllby R. Isolation and properties of membrane damaging toxins. In: Easmon CSF, Adlam C (eds) Staphylococci and staphylococcal infections, vol. 2: the organism in vivo and in vitro. London, Academic Press, 1983: 619-669.

20. Kingdom JCP, Joyce SM, Bradley FL, Jauch W, Falkiner FR, Keane CT. Staphylococcal nasal carriage in medical students with varying clinical exposure. J Hosp Infect 1983; 4: 75-79.

21. Cove JH, Eady EA, Cunliffe WJ. Skin carriage of antiobioticresistant coagulase-negative staphylococci in untreated subjects. $J$ Antimicrob Chemother 1990; 25: 459-469.

22. Parsonnet J, Harrison AE, Spencer SE, Reading A, Parsonnet $\mathrm{KC}$, Kass EH. Nonproduction of toxic shock syndrome toxin 1 by coagulase-negative staphylococci. J Clin Microbiol 1987; 25: $1370-1372$.

23. Mollitt DL, Tepas JJ, Talbert JL. The role of coagulasenegative staphylococcus in neonatal necrotizing enterocolitis. $J$ Pediatr Surg 1988; 23: 60-63.

24. Scheifele DW, Bjornson GL. Delta toxin activity in coagulasenegative staphylococci from the bowels of neonates. J Clin Microbiol 1988; 26: 279-282.

25. Scheifele DW, Bjornson GL, Dyer RA, Dimmick JE. Delta-like toxin produced by coagulase-negative staphylococci is associated with neonatal necrotizing enterocolitis. Infect Immun 1987; 55: 2268-2273.

26. Gemmell CG, Roberts CE. Toxins and enzymes of coagulase negative staphylococci isolated from human infections. $J \mathrm{Hyg}$ Epidemiol Microbiol Immunol 1974; 18: 261-266.

27. Hovelius B, Mardh PA, Bygren P. Urinary tract infections caused by Staphylococcus saprophyticus: recurrences and complications. J Urol 1979; 122: 645-647.

28. Cooper BC, Alleva M, Cooper DL, Lucente FE. Myofascial pain dysfunction: analysis of 476 patients. Laryngoscope 1986; 96: $1099-1106$.

29. McKevitt AI, Bjornson GL, Mauracher CA, Scheifele DW. Amino acid sequence of a deltalike toxin from Staphylococcus epidermidis. Infect Immun 1990; 58: 1473-1475.

30. Dhople VM, Nagaraj R. Generation of analogs having potent antimicrobial and haemolytic activities with minimal changes from an inactive 16-residue peptide corresponding to the helical region of Staphylococcus aureus delta-toxin. Protein Eng 1995; 8: 315-318.

31. Mellor IR, Thomas DH, Sansom MS. Properties of ion channels formed by Staphylococcus aureus delta toxin. Biochim Biophys Acta 1988; 942: 280-294.

32. Kapral FA. Inhibition of Staphylococcus aureus delta haemolysin by phospholipids. Proc Soc Exp Biol Med 1972; 141: 519-521. 
33. Kapral FA. Effect of fatty acids on Staphylococcus aureus deltatoxin hemolytic activity. Infect Immun 1976; 13: 114-119.

34. Long JP, Kapral FA. Host response to coagulase-negative staphylococci in abscesses induced within mice. $J$ Med Microbiol 1993; 39: 191-195.

35. Kapral FA, Smith S, Lal D. The esterification of fatty acids by Staphylococcus aureus fatty acid modifying enzyme (FAME) and its inhibition by glycerides. J Med Microbiol 1992; 37: 235-237.
36. McCulley JP, Dougherty JM. Bacterial aspects of chronic blepharitis. Trans Ophthalmol Soc UK 1986; 105: 314-318.

37. Wadström T. Biological effects of cell damaging toxins. In: Easmon CSF, Adlam C (eds) Staphylococci and staphylococcal infections, vol 2: the organism in vivo and in vitro. London, Academic Press, 1983: 671-704.

38. Turner WH, Pickard DJ. A new haemolysin from Staphylococcus aureus which lyses horse erythrocytes. $J$ Gen Microbiol 1980; 116: 237-241. 